\title{
Corrosion Inhibition of Aluminum in Aqueous Alkaline Solutions by Alginate and Pectate Water-Soluble Natural Polymer Anionic Polyelectrolytes
}

\author{
I. Zaafarany* \\ Chem. Dept. Faculty of Appl. Sci., Umm Al-qura University, Makkah Al-Mukaramha, Saudi Arabia
}

Received 13 January 2013; accepted 13 February 2013

\begin{abstract}
The influence of water-soluble alginates (Alg) and pectates (Pect) anionic polyelectrolytes as natural polymers containing secondary alcoholic groups on the rate of dissolution of aluminum metal in alkaline medium has been investigated by gasometric and weight-loss techniques. The results showed that addition of alginates or pectates to the tested solutions leads to a remarkable decrease in the corrosion rate of $\mathrm{Al}$ in $\mathrm{NaOH}$. The magnitude of inhibition efficiency was found to be larger in case of pectates. Factors affecting the corrosion process such as the concentration of the inhibitor and the corrosion medium, structure of the inhibitor and temperature have been examined. The kinetic parameters of corrosion have been evaluated and a suitable mechanism for the inhibition is discussed.
\end{abstract}

Keywords: corrosion, inhibitors, anionic, polyelectrolytes, aluminum, kinetics.

\section{Introduction}

The development of inhibitors for aluminum corrosion in aqueous solution, in particularly in alkaline media has attracted many investigators. However, the influence of inhibitors has been the subject of numerous investigators; the corrosion mechanisms as well as the role of inhibitors are not completely explained.

Although many organic [1-7], inorganic [8,9] and synthesized polymeric [10,11] compounds were applied as inhibitors for reducing the aluminum corrosion in alkaline media, little attention has been focused for applying natural polymers as inhibitors [12]. Indeed, sulfated carrageenan $[13,14]$ and carboxymethyl cellulose $[15,16]$ as natural polymers as well as polyacrylic acid [17] as a synthetic

\footnotetext{
*Corresponding author. E-mail: ishaq_zaafarany@yahoo.com
} 
polymer have been successfully used as inhibitors for corrosion of iron in acidic media.

In view of the above aspects, the present work of using alginate and pectate polysaccharides as natural polymeric inhibitors for $\mathrm{Al}$ metal in $\mathrm{NaOH}$ has been undertaken with a view at shedding some lights on the mechanism of corrosion. In addition, it is of interest to extend our work carried out in our laboratory on natural polymers, particularly on polysaccharides, as a part of a series of investigations [18-23].

\section{Experimental \\ Materials}

All materials used were of analytical grade. Doubly distilled water was used in all preparations. The temperature was controlled within $\pm 0.1{ }^{\circ} \mathrm{C}$.

Sodium alginate and sodium pectate (Fluka) were used without further purification. Aluminum metal used was 99.98 purity (Ventron Corp, Japan). The degrees of substitution for alginates and pectates (apple) were found to be 3.84 and $4.12 \mathrm{~mol} / \mathrm{g}(0.7$ and $0.64 \mathrm{~mol} / \mathrm{mol})$, respectively. Again, the inherent viscosities measured by using Ubbelhode viscometer were found to be 3.84 and $0.8 \mathrm{dL} / \mathrm{g}$ for alginates and pectates, respectively.

\section{Preparation of alginate and pectate sols}

Alginate and pectate sols were prepared as described elsewhere [18-22]. This process was performed by stepwise addition of the powder reagent to bidistilled water whilst vigorously stirring the solutions to avoid the formation of lumpy precipitates, which swell with difficulty.

\section{Techniques of measurements}

The rates of corrosion were determined volumetrically. This process takes place by measuring the evolved hydrogen produced from dissolution of aluminum in $\mathrm{NaOH}$. Rectangular specimen of metal aluminum of $3 \mathrm{~cm}$ long and $1.9 \mathrm{~cm}$ in diameter were used without further polishing to ensure reproducible surface. However, they were washed with carbon tetrachloride, absolute ethyl alcohol and then dried in acetone and stored in free desiccators prior to the use in corrosion testing. The specimens were suspended by means of a glass hook in the tested solutions of $\mathrm{NaOH}$ which were previously placed into a conical flask fitted with a graded side-arm burette filled with bidistilled water as described elsewhere $[17,24,25]$. The conical flasks were thermostated in a controlled water-bath at the desired temperature within $\pm 0.1{ }^{\circ} \mathrm{C}$. When the $\mathrm{NaOH}$ solution had attained the temperature of the thermostat, the $\mathrm{Al}$ specimen was immersed into the alkali solution. The course of reaction was followed gasometrically by recording the volume of evolved hydrogen as a function of time.

Some kinetic measurements were performed using the classical weight-loss method [25] in order to check the reproducibility of the gasometric data obtained. The analyses of the results obtained were found to be in a good agreement with 
each other within the experimental errors $( \pm 4 \%)$. This fact may indicate the reproducibility of the results obtained, gasometrically.

All experiments were repeated using different concentrations of $\mathrm{NaOH}$ and inhibitors at various temperatures. The results used were at least an average of five experimental runs. No stirring of the corrosion medium was employed.

\section{Results}

The volume of the evolved hydrogen (or the loss in weight of Al metal) as a function of time may be taken as the rate of dissolution of aluminum in sodium hydroxide as is illustrated by Eqs. (1) and (2), respectively,

$$
\begin{aligned}
& R_{c}=\frac{V_{H}}{\mathrm{St}} \\
& R_{c}=\frac{\Delta W}{\mathrm{St}}
\end{aligned}
$$

where $R_{c}$ is the rate of corrosion, $\mathrm{S}$ is the surface area of $\mathrm{Al}$ metal $\left(\mathrm{cm}^{2}\right), \mathrm{t}$ is the time (min), $V_{H}$ is the volume of evolved hydrogen $(\mathrm{mL})$ and $\Delta \mathrm{W}$ is the loss in mass (mg) of $\mathrm{Al}$ metal into the corrosive medium.

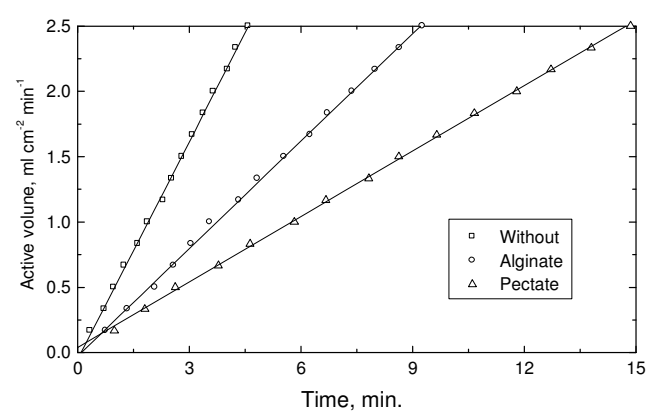

Figure 1. Plots of hydrogen evolved vs. time for the corrosion of aluminum in sodium hydroxide in the absence and presence of $0.4 \%$ inhibitor and $\left[\mathrm{OH}^{-}\right]=4.0 \mathrm{~mol} \mathrm{dm}^{-3}$ and $\mathrm{I}=4.0 \mathrm{~mol} \mathrm{dm}^{-3}$ at $25{ }^{\circ} \mathrm{C}$.

Typical plots are shown in Figs. 1 and 2, respectively. The rate of corrosion can be obtained from the slopes of such plots. The values of $R_{c}$ were calculated by using the method of least-square and are summarized in Table 1.

The percentage inhibition efficiency (I.E \%) of the selected alginate and pectate polysaccharides as natural polymeric inhibitors was calculated using the following equation

$$
\% \text { I.E }=\frac{{R_{c}{ }^{o}-R_{c}{ }^{\prime}}_{R_{c}{ }^{o}}}{R^{\prime}} x 100
$$

where $R_{c}{ }^{o}$ and $R_{c}$ ' are the corrosion rates of $\mathrm{Al}$ metal in the absence and presence of natural polymeric inhibitors, respectively. 


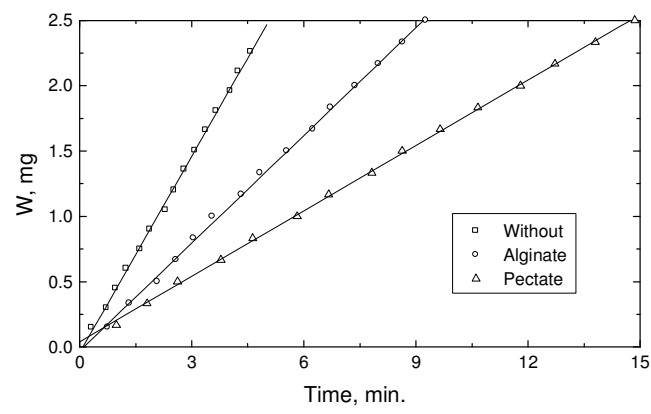

Figure 2. Plots of weight-loss vs. time for the corrosion of aluminum in sodium hydroxide in the absence and presence of $0.4 \%$ inhibitor and $\left[\mathrm{OH}^{-}\right]=4.0 \mathrm{~mol} \mathrm{dm}^{-3}$ and $\mathrm{I}=4.0 \mathrm{~mol} \mathrm{dm}^{-3}$ at $25^{\circ} \mathrm{C}$.

Table 1. Rate of corrosion $\left(R_{c}, \mathrm{~mL} / \mathrm{cm}^{2} . \mathrm{min}\right)$ of aluminum in alkaline medium in the presence and absence of added inhibitors. $\left[\mathrm{OH}^{-}\right]=4.0 \mathrm{~mol} \mathrm{dm}^{-3}$ and $\mathrm{I}=4.0 \mathrm{~mol} \mathrm{dm}{ }^{-3}$.

\begin{tabular}{|c|c|c|c|c|}
\hline Temp. $\left({ }^{\mathbf{0}} \mathbf{C}\right)$ & \multicolumn{2}{|c|}{25} & \multicolumn{2}{c|}{35} \\
\hline Inhibitor (\%) & Alginate & Pectate & Alginate & Pectate \\
\hline $\mathbf{0 . 0}$ & \multicolumn{2}{|c|}{0.38} & \multicolumn{2}{c|}{0.87} \\
\hline $\mathbf{0 . 4}$ & 0.28 & 0.17 & 0.67 & 0.58 \\
\hline $\mathbf{0 . 6}$ & 0.22 & 0.12 & 0.53 & 0.41 \\
\hline $\mathbf{0 . 8}$ & 0.16 & 0.08 & 0.40 & 0.28 \\
\hline $\mathbf{1 . 2}$ & 0.07 & 0.06 & 0.21 & 0.18 \\
\hline
\end{tabular}

\section{Discussion}

It is well known that increasing the $\left[\mathrm{OH}^{-}\right]$will increase the activity of $\mathrm{OH}^{-}[26]$ and, hence, should increase the dissolution of $\mathrm{Al}$ metal as was experimentally observed. The observed fractional-order for $\left[\mathrm{OH}^{-}\right]$-dependence of the corrosion rates means that at least one of the corrosion paths of $\mathrm{Al}$ metal in $\mathrm{NaOH}$ should involve hydroxide ion in the rate-determining step.

On the other hand, it was observed that the addition of either alginate or pectate sol to the tested solutions of $\mathrm{Al}$ metal in $\mathrm{NaOH}$ is accompanied by a remarkable decrease in the corrosion rate of aluminum.

In view of the above interpretations and the experimental observations, a suitable mechanism for corrosion may be suggested. It involves the electrochemical process [27] resulting from dissolution of $\mathrm{Al}$ metal in the alkali. This process can be expressed by anodic and cathodic processes, Eqs. (4) and (5), respectively:

$$
\begin{aligned}
& \mathrm{Al}+4 \mathrm{OH}^{-} \stackrel{O x}{\rightleftharpoons} \mathrm{Red} \\
& \mathrm{H}_{2} \mathrm{O}+\mathrm{e} \stackrel{\mathrm{ReH})_{4}^{-}+3 \mathrm{e}}{\rightleftharpoons} 1 / 2 \mathrm{H}_{2}+\mathrm{OH}^{-}
\end{aligned}
$$

The overall electroochemical process is 


$$
2 \mathrm{Al}+2 \mathrm{OH}^{-}+6 \mathrm{H}_{2} \mathrm{O} \longleftrightarrow 2 \mathrm{Al}(\mathrm{OH})_{4}^{-}+3 \mathrm{H}_{2}
$$

Alginates and pectates are water-soluble polysaccharides of linear block copolymer structures consisting of D-mannuronic and L- gulurunic acid units linked through $\beta(1 \rightarrow 4)$ positions [28]. The principal structural difference between them is the position of the two C-2 and C-3 hydroxyl groups being cisposition in alginates and trans-position in pectates, respectively. When the conformation is considered, axial-equatorial and equatorial-equatorial exist. These natural polymers are anionic in nature owing to the presence of carboxylate groups. The carboxylate groups probably being equatorial in both [29]. These polysaccharides are assumed to be deprotonated in alkaline solutions to give the corresponding reactive alkoxides $[18,20]$ as follows:

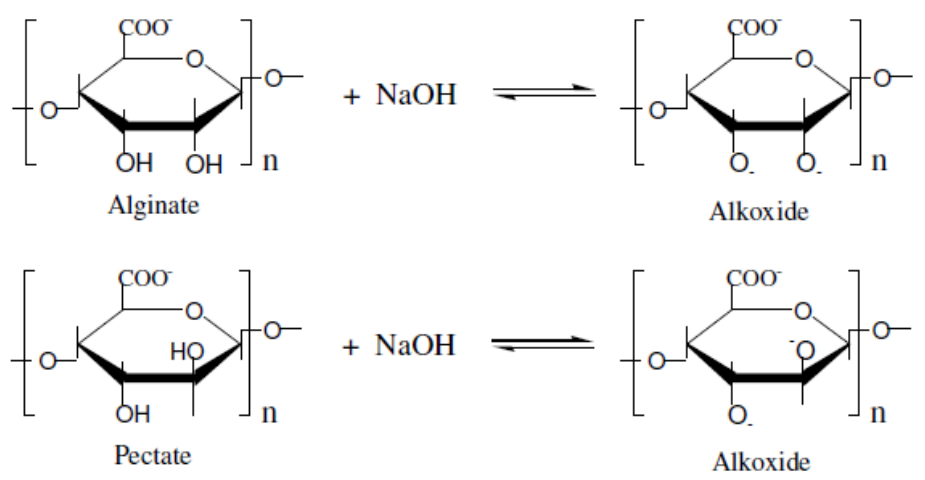

It has been reported [30] that the inhibitor can affect the corrosion rate of metals in the corrosive media if it is able to affect the kinetics of dissolution or alter the position of electrochemical behaviour. This effect takes place when a thin film of an inhibitor is formed on the surface of the metal by either the interaction or adsorption processes. The protective film will isolate the metal from the corrosive medium, i.e. it decreases the corrosion rate. Under the influence of highly negative potentials such as in case of Al metal in alkaline solutions [3035], all anionic organic compounds are expelled by the electric double layer and, hence, cannot affect the corrosion rate significantly. On the other hand, the cationic material strongly inhibits the corrosion processes owing to its adsorption on the metal surface.

As shown in Table 1, addition of small amounts of alginates or pectates as anionic polyelectrolytes to $\mathrm{Al}$ in $\mathrm{NaOH}$ leads to a remarkable inhibition of the corrosion rates of aluminum metal. This result may be explained by the adsorption of negative alkoxides formed by the deprotonation processes or the anionic polymer itself on the positive sites which may be formed as a result of electrons liberation in the anodic processes. The net result of adsorption is the formation of an inhibitor thin film on the aluminum surface. The formed film will prevent more $\mathrm{Al}$ atoms from leaving the metal surface to dissolve in the corrosive medium. This means that the corrosion rate is decreased. Therefore, the anodic reaction may be suggested to be the rate-determining step in the present corrosion process. Again, the presence of lone pairs of electrons on the oxygen atoms of the hydroxyl groups may enhance the interaction between the inhibitors and the positive sites formed on Al surface. Moreover, Khairou and El-Sayed 
[36] reported that the functional hydroxyl groups of the natural-polymer anionic polyelectrolytes could form bridges between the polymer and the metal surface and, hence, affecting the inhibition behavior.

Table 2. Inhibition efficiency percentage (\% I.E.) for corrosion of aluminum in alkaline medium. $\left[\mathrm{OH}^{-}\right]=4.0 \mathrm{~mol} \mathrm{dm}{ }^{-3}$ and $\mathrm{I}=4.0 \mathrm{~mol} \mathrm{dm}{ }^{-3}$ at $30^{\circ} \mathrm{C}$.

\begin{tabular}{|c|c|c|c|c|c|}
\hline Inhibitor (\%) & 0.4 & 0.6 & 0.8 & 1.2 & 1.6 \\
\hline Alginate & 26.5 & 44.66 & 58.33 & 78.17 & 86.66 \\
\hline Pectate & 46.67 & 62.23 & 72.67 & 81.67 & 88.67 \\
\hline
\end{tabular}

The inhibition efficiency (\% I.E) was found to increase with increasing the concentration of the added inhibitors as shown in Table 2. The magnitude of the I.E was found to be larger in case of pectates rather than in alginates. The inhibition efficiency may be affected by many factors such as the adsorption of the additives on Al metal surface which depend on some physicochemical properties, e.g., the functional groups, steric factors and electronic and geometrical configurations of the inhibitor [13,14]. The geometrical structure of the hydroxyl groups in C-2 and C-3 may play an important role in this behavior. The presence of $\mathrm{OH}$ groups in cis-position in alginates tends to decrease the ability of adsorption of the inhibitors on Al metal surface owing to the hindrance effect, compared with that in case of pectates where the $\mathrm{OH}$ groups exist in the trans-position. Here, the hindrance effect is relatively small. This may explain the small inhibition effects of alginates compared to that of pectates.

The orders with respect to the alginate and pectate inhibitors concentrations (log [Inhibitor] vs. $\log R_{c}$ ) were found to be $1.4 \pm 0.1$ and $1.2 \pm 0.1$, respectively. The magnitude of this order may also reflect the efficiency of the inhibitor on the corrosion rate. In addition, the fractional order observed with respect to alginate and pectate concentrations may indicate the formation of intermediates through the adsorption process. Furthermore, the kinetic parameters of the corrosion inhibition were calculated from the dependence of the corrosion rate on the temperature. This dependence was found to fit the Arrhenius and Eyring relationships [37], which required that plots of $1 / \mathrm{T}$ vs. $\ln R_{c}$ or $1 / \mathrm{T}$ vs. $\ln$ $\left(\mathrm{h} R_{c} / \mathrm{RT}\right)$ for Arrhenius and Eyring equations, respectively, to be linear with positive intercepts on $\mathrm{Y}$ axes as was experimentally observed. The kinetic parameters can be evaluated from the slopes and intercepts of such plots. The values of the kinetic parameters were calculated using the least-square method and are summarized along with that of poly(vinyl alcohol) as synthetic polymers [38] in Table 3. The positive values of $\Delta \mathrm{H}^{\#}$ reflect the endothermic process of adsorption of the inhibitors on $\mathrm{Al}$ surface. The negative values of $\Delta \mathrm{S}^{\#}$ may reflect the association mechanism of corrosion, i.e., the decrease in disorderly takes place on going from reactants to the activated states [13].

It is also noticed that addition of small amounts of the inhibitor to the tested solutions alters the values of $\Delta S^{\#}$ (in absence of inhibitors) to a less negative one, i.e., inhibits the corrosion rates. This result may be considered as an indirect evidence to support the proposed mechanism. 
Table 3. Kinetic parameters of corrosion of Aluminum in alkaline medium in the presence and absence of added natural and synthetic polymers containing secondary alcoholic groups.

\begin{tabular}{|c|c|c|c|c|c|c|c|}
\hline Inhibitor & $\begin{array}{c}\text { Conc. } \\
(\%)\end{array}$ & $\begin{array}{c}\Delta H^{\ddagger} \\
\mathrm{kJ} \mathrm{mol}^{-1}\end{array}$ & $\begin{array}{c}\Delta S^{\ddagger} \\
\mathbf{J} \mathbf{m o l}^{-1} \mathbf{K}^{-1}\end{array}$ & $\begin{array}{c}\Delta G^{\neq} \\
\mathrm{kJ} \mathrm{mol}^{-1}\end{array}$ & $\begin{array}{c}E_{a}^{\neq} \\
\mathrm{kJ} \mathrm{mol}^{-1}\end{array}$ & $\begin{array}{c}\mathbf{A} \\
\mathrm{mol}^{-1} \mathbf{s}^{-1}\end{array}$ & Ref. \\
\hline Without & $\mathbf{0}$ & 58.85 & -61.97 & 77.31 & 53.75 & $1.11 \times 10^{11}$ & This work \\
\hline \multirow[b]{2}{*}{ Alginate } & 0.4 & 69.86 & -24.56 & 76.16 & 71.98 & $1.46 \times 10^{11}$ & This work \\
\hline & 0.8 & 68.93 & -22.02 & 77.58 & 70.86 & $2.22 \times 10^{12}$ & This work \\
\hline \multirow[b]{2}{*}{ Pectate } & 0.4 & 76.93 & -2.78 & 77.21 & 78.75 & $1.11 \times 10^{13}$ & This work \\
\hline & 0.8 & 78.49 & -1.75 & 79.01 & 79.64 & $8.01 \times 10^{12}$ & This work \\
\hline \multirow[b]{2}{*}{ PVA } & 0.4 & 51.85 & -79.88 & 75.66 & 55.75 & $1.99 \times 10^{9}$ & 38 \\
\hline & 0.8 & 51.56 & -82.44 & 76.13 & 55.85 & $1.69 \times 10^{9}$ & 38 \\
\hline
\end{tabular}

\section{Conclusion}

1. We have proved (Table 1 and Fig. 1) that alginate and pectate anionic polyelectrolytes as natural polymers are effective inhibitors for corrosion of aluminum in alkaline medium.

2. Pectates are more active for corrosion inhibition than alginates. This may be due to the geometrical configuration of the functional groups of the inhibitors, which play an important role in the magnitude of inhibition efficiency.

3. We would believe that natural or synthetic polymers containing the same functional groups will have the same corrosion behavior and, hence, may proceed through similar corrosion mechanism.

\section{References}

1. Ramakrishnaih K, Subramanyan N. Corr Sci. 1976;16:307. Ramakrishnaih K, Subramanyan N. J Electrochem Soc. 1969;18:21. Ramakrishnaih K, Subramanyan N. J Electrochem Soc. 1970;8:369.

2. Taiati JD, Mold RM. Corr Sci. 1979;19:35.

3. Daufin G, Labre JP, Pagetti J. Corr Sci. 1977;17:901.

4. Solyneos KG, Varhegyi B, Kalman E, Karman FH, Gal M, Hencsei P, Bihatsi L. Corr Sci. 1993;35:1455.

5. Rosilda LGS, Ganeson M, Kulondainathan MA, Kapali V. J Power Sour. 1994;50:321.

6. $\quad$ Muller B, Fisher S. Corr Sci. 2006;48:2604.

7. Lunarska E, Chernagayeva O. Inter J Hydrogen Eng. 2006;31:285.

8. Awad SA, Kamal KhM, Kassab A. J Electroanal Chem. 1981;127:203.

9. Arenos MA, Bethencourt M, Botana FG, Domborenena J, Marcos M. Corr Sci. 2001;43:157.

10. Muller B, Schmelich T. Corr Sci. 1995;37:877. Muller B, Oughourlian C, Schubert M. Corr Sci. 2000;42:577. Muller B, React Funct Polym. 1999;39:165.

11. Amin MA, Hazzazi OA, Abd El-Rhim S, El-Sherbini EF, Abbas MN. Corr Sci. In press.

12. Gaber AMA, Khamis E, El-Dahab HA, Adel Sh. Mater Chem Phys. 2008;109:297.

13. Zaafarany E. Current World Environ. 2006;12:101. 
14. Khairou KS, Zaafarany IA. Mater Sci Res Ind. 2006;3:135.

15. Umoren SA, Solomon MM, Udsoro II, Udoh AP. Cellulose. 2010;17:635.

16. Solomon MM, Umoren SA, Udosoro II, Udoh AP. Corr Sci. 2010;52:1317. Umoren SA, Li Y, Wang FH. J Sol State Electrochem. 2010;14:2293.

17. Sorkhabi HA, Jeddi NG, Hashemzadeh F, Jahani H. Electrochim Acta. 2006;51:3848.

18. Zaafarany IA, Khairou KS, Hassan RM. J Mol Cat. 2009;302:112. Abdel-Hamid MI, Khairou KS, Hassan RM. Eur Polym J. 2003;39:381. Hassan RM. J Polym Sci. 1993;31:1147. Khairou KS, Hassan RM. Eur Polym J. 2000;36:2021.

19. Hassan RM, Wahdan MH, Hassan A. Eur Polym J. 1988;24:281. Hassan RM, ElShatoury SA, Mousa MA. Eur Polym J. 1988;24:2273. Hassan RM, Summan AM, El-Shatoury SA. Eur Polym J. 1989;25:1209. Khairou KS, El-Gethami WM. J Memb Sci. 2002;209:445.

20. Hassan RM. J Mol Sci. 1991;26:5806. Hassan RM. J Mol Sci. 1993;28:384. Hassan RM, Awad A, Hassan A. J Polym Sci A. 1991;29:1645. Hassan RM. Polym Int. 1993;31:81. Hassan RM, Makhlouf MTh, El-Shatoury SA. Colloid Polym Sci. 1992;270:1237.

21. Hassan RM. High Perform Polym. 1989;1:275. Hassan RM, Makhlouf MTh, Summan AM, Awad A. Eur Polym J. 1989;25:1993. Hassan RM. Coll. Surf., 60, 203 (1991), Hassan RM, Ikeda Y, Homiyasu H. J Mater Sci. 1993;28:5143. Khairou KS, Hassan RM. High Perform Polym. 2002;14:93. Zaafarany IA, Khairou KS, Hassan RM. High Perform Polym. In press.

22. Said AA, Hassan RM. Polym Degrad Stab. 1993;39:393. Said AA, Abd El-Wahab MM, Hassan RM. Thermochim Acta. 1994;233:13. El-Gahami MA, Khairou KS, Hassan RM. Bull Polym Acad Sci. 2003;51:105.

23. Hassan RM, Abd Alla MA, El-Zohry MF. J Appl Polym Sci. 1993;47:1649. KhairouKS, Hassan RM, Shaker A. J Appl Polym Sci. 2002;85:1019. Hassan RM, Abd Alla MA. J Mol Chem. 1992;2:609.

24. Driske TB, Timmer RM. J Electrochem Sci Tech. 1969;116:162.

25. Vorkapic LZ, Drazic DM, Despic AR. J Electrochem Sci Tech. 1974;121:1385.

26. Akerlof GC, Bender P. J Am Chem Soc. 1948;70:2366.

27. Rezenfeld IL. Corrosion inhibitors. New York: McGraw-Hill Inc; 1981.

28. Muzarelli RAA. Natural chelating polymers. $1^{\text {st }}$ ed. Oxford: Pergamon Press; 1973.

29. Schwieger RG. J Org Chem. 1962;27:1789. Schwieger RG. Koll Z. 1964;196:47. Rees DA. Biochem J. 1972;126:257. Rees DA. Chem Ind (London). 1972;630.

30. McCafferty E. Corrosion control by coating. Leidheiser Jr H, editor. New Jersey: Science Press; 1979.

31. Antropov N, Pogrebova IS. Advances in science and technology, corrosion and protection of metals. Izdat, Moscow. 1973;2:27.

32. VV Damaskin, OA Petrii, Batrakov VV. The adsorption of organic compounds on electrodes. Mocow: Nauka; 1968.

33. Annaud RR, Hurd RM, Hackerman N. J Electrochem Soc. 1965:112;138.

34. Gierst L, Herman P. Z Anal Chem. 1966;216:238.

35. Narayan R. An introduction to metallic corrosion and its prevention. New Delhi: Oxford and IBH Publishing Company; 1983.

36. Khairou KS, El-Sayed A. J Appl Polym Sci. 2003;88:866.

37. S Glasstone, KJ Laider, Eyring H. The theory of the rate processes. New York: McGraw-Hill; 1941. P. 141.

38. Zaafarany IA, Hassan R. Private communication. 